\title{
Refinamento de Buscas na Internet para Professores de Matemática do Ensino Fundamental II
}

\author{
Eduardo Barrére, Elias Antonio Almeida da Fonseca \\ Universidade Federal de Juiz de Fora (UFJF) - MG - Brazil \\ \{eduardo.barrere, elias.antonio\}@ice.ufje.br
}

\begin{abstract}
The use of Digital Information and Communication Technologies (TDICs) for public school teachers involves factors related to insertion of technology in education and ways of use policy. This paper presents a frontend to the Google search engine, which aggregates Semantic Web and terms of the PCN to enhance the search for digital educational contents for teachers of mathematics at middle school, facilitating the search for appropriate content on the Internet.
\end{abstract}

Resumo. O uso de Tecnologias Digitais de Informação e Comunicação (TDICs) por professores de escolas públicas envolve fatores relacionados á política de inserção da tecnologia na educação e modos de utilização. $O$ presente trabalho apresenta um front-end para o mecanismo de busca Google, que agrega Web Semântica e termos do PCN para aprimorar a busca por conteúdos educacionais digitais por professores de matemática do Ensino Fundamental II, facilitando a busca de conteúdos apropriados na internet.

\section{Introdução}

No campo da educação, o uso da tecnologia para apoio didático se consolidou nas últimas décadas do século XX com a popularização da internet e das demais tecnologias digitais. O processo de inserção da tecnologia na educação pública brasileira trouxe consigo não apenas oportunidades, mas também deu origem, a diferentes tipos de conflitos, que permanecem até os dias atuais.

Fatores, como as longas jornadas de trabalho exercidas por grande parte dos professores de escolas públicas, falta de formação continuada e valorização profissional, entre outros, dificultam a utilização dos recursos tecnológicos para apoio didático pedagógico na escola. Neste contexto, é importante analisar os diversos pontos de vistas relacionados aos processos de inserção da tecnologia na escola dentro de uma perspectiva didático pedagógica. Este trabalho faz essa análise e apresenta como contribuição principal uma ferramenta que encapsula (front-end) o acesso ao mecanismo de busca Google, visando o refinamento da busca de forma transparente para o professor, ou seja, sem que ele necessite ter conhecimentos aprofundados de técnicas e refinamentos de pesquisa na internet.

Nesta Perspectiva, o presente artigo está organizado da seguinte forma: a seção 2 apresenta reflexões sobre o processo de inserção da tecnologia na educação pública brasileira e a formação profissional docente no contexto de utilização dos recursos tecnológicos para apoio didático no processo de ensino e aprendizagem da matemática, 
a seção 3 apresenta um levantamento realizado para mapear as principais dificuldades dos professores para com o uso de Tecnologias Digitais da Informação e Comunicação TDICs, a seção 4 apresenta a ferramenta proposta e, por último, a seção 5 apresenta as considerações finais e trabalhos futuros.

\section{Uso da Tecnologia e Cenário da Educação Pública no Brasil}

O processo de incorporação da tecnologia e o cenário da educação pública do Brasil apresentam uma variedade de conflitos que dificultam o desempenho das atividades pedagógicas, mediadas pelo professor, com a presença dos recursos tecnológicos para serem utilizados como recursos didáticos. É importante ressaltar que a finalidade principal de integrar a tecnologia ao ensino é tê-la como auxiliar nas atividades de ensino e aprendizagem. Entretanto, o discurso acerca do uso da tecnologia como recurso didático, muitas vezes, é tratado teoricamente nas escolas públicas do Brasil com o intuito de emitir relatórios duvidosos de produtividade na aprendizagem para cumprimento de metas dos programas de governos [Carvalho 2012].

Em diversas escolas, os poucos professores que se dispõem a utilizar os recursos tecnológicos para uso didático, são desafiados a criar seus próprios métodos e trabalhar de forma isolada dos demais colegas que não utilizam. Nesse cenário desanimador temse muitas vezes a contradição de existirem computadores na escola, mas na grande maioria das vezes não integrados às práticas pedagógicas diárias dos professores e ao processo de construção de conhecimentos dos alunos. Os motivos pelos quais isso ocorre vão desde a falta de projeto pedagógico adequado até a questão do preparo dos professores para efetivar tal integração [Carvalho 2012] [Bairral 2013].

É inegável que nos últimos tempos a escola pública tenha sido alvo de grandes investimentos em material pedagógico para o processo de ensino e aprendizagem. Programas de governos, como por exemplo, o Plano de desenvolvimento da escolaPDE, tem a finalidade de dar apoio ao desenvolvimento da escola, possibilitando a aquisição de material didático pedagógico e o desenvolvimento de atividades relacionadas aos projetos sugeridos pela equipe escolar. No entanto, existe um descompasso entre a teoria e a prática que dificulta a democratização do processo de inserção da tecnologia como recurso didático. Existem escolas que são exemplos diferenciados na condução da democratização da utilização dos recursos tecnológicos, tais escolas privilegiadas com iniciativas de professores, ONGs e de políticas públicas que promovem o desenvolvimento de projetos que podem ser tomados como referência.

\subsection{Processo de Inserção da Tecnologia na Educação}

Bairral (2013) argumenta sobre a necessidade dos futuros professores de matemática, durante sua formação inicial, em utilizar a tecnologia em situação de aprendizagem com o objetivo de refletir o processo de inserção não apenas teoricamente. Mas, entender como se aprende usando a tecnologia, desse modo estariam acumulando experiências reais que podem ser utilizadas com seus futuros alunos em sala de aula.

Salienta-se que o uso da tecnologia no apoio didático pedagógico exige do professor algumas horas de planejamento semanal, no entanto, fatores como a falta de tempo para um planejamento mais detalhado das aulas por muitos professores, devido ás longas jornadas que devem cumprir, dificulta a utilização da tecnologia no apoio 
didático. Uma possível solução para este problema em escolas públicas pode ser o aumento do tempo de horas das atividades complementares (AC) do professor na escola. Contudo, é necessário que haja para cada escola, um professor articulador de cada área de ensino trabalhando junto com o coordenador pedagógico, com a finalidade de instigar o professor a desenvolver atividades diferenciadas que utilizem recursos tecnológicos.

Nesse sentido, a Secretaria de Educação do Estado da Bahia é uma das pioneiras em aumentar a carga destinada à realização de atividades de planejamento de cada professor para 1/3 da carga da carga horária total (Lei $\mathrm{n}^{\circ} 12$. 904, publicada no Diário Oficial da Bahia em 18/09/2013). Desse modo, um professor que trabalha com uma carga horária de 40 horas semanais, terá 26 horas/aulas para as atividades em salas de aula com alunos e 14 horas para planejamento.

Nas últimas décadas, o governo brasileiro tem investido em projetos que têm por finalidade promover a utilização de novos recursos tecnológicos no espaço escolar, tanto por professores, como por alunos. No entanto, é preciso refletir sobre como e quais são as condições de utilização desses recursos nos aspectos didáticos pedagógicos.

Dentre muitos programas fomentados pelas políticas públicas, vale destacar, o "Programa Um Computador por Aluno" (PROUCA), Instituído pela Lei no 12.249, de 14 de junho de 2010, cujo principal objetivo é promover a inclusão digital pedagógica e o desenvolvimento dos processos de ensino aprendizagem de alunos e professores das escolas públicas brasileiras, mediante a utilização de computadores portáteis denominados laptops educacionais. Este programa é uma iniciativa que pode contribuir não apenas para o processo de inserção da tecnologia na escola, mas principalmente para integrar e melhor aproveitar recursos tecnológicos para apoio didático.

\subsection{Uso de TDICs no Processo de Ensino e Aprendizagem de Matemática}

$\mathrm{O}$ uso da tecnologia no processo de ensino e aprendizagem deve ser incorporado na escola como recurso para auxiliar na aprendizagem do aluno, sem a pretensão de abolir o ensino tradicional, mas sim permitir outras formas de aprendizagem. Esse uso deve ser precedido de um planejamento. O professor deve apropriar-se de uma metodologia, com objetivos bem definidos. O mero uso da tecnologia em sala de aula ou no laboratório de informática, sem um planejamento, pode implicar na subutilização dos recursos tecnológicos, como destacado por Boeri and Silva (2011):

\footnotetext{
Os profissionais que se mostram otimistas quanto ao uso do computador como apoio às aulas, muitas vezes apresentam razões pouco estruturais, decorrentes de grande euforia quanto à nova tecnologia, que pode levar a desapontamentos.
}

Castro Filho (2007) argumenta que apesar de muitos professores acessarem a internet em busca de informações e materiais didáticos para enriquecimento das aulas e melhora da prática pedagógica, estes professores aproveitam pouco o real potencial que os recursos tecnológicos podem oferecer, vários são os fatores que provocam esta situação, dentre eles: a grande quantidade de informações apresentadas nos buscadores automáticos (O Google, o Yahoo, entre outros), que dificultam o retorno refinado da informação desejada, a complexidade de utilização de muitos softwares educacionais, etc. Outros professores não utilizam recursos tecnológicos por serem conscientes que não possuem uma metodologia para planejamento das aulas. 
Segundo Borba (2010), de modo geral, utilizar tecnologias informáticas, em um ambiente de ensino e aprendizagem, requer a sensibilidade do professor ou pesquisador para optar por estratégias pedagógicas que permitam explorar as potencialidades desses recursos, tornando-os didáticos.

\section{Pesquisa sobre o uso de recursos educacionais em escolas públicas}

No intuito de compreender quais as dificuldades para utilização das TDICs pelos professores de escolas públicas da cidade de Itamaraju, localizada no extremo sul da Bahia, local de aplicação da pesquisa, optou-se pela utilização de um questionário para coleta de dados. Este questionário foi composto por dez questões, todas de múltipla escolha, que abordavam dificuldades relacionadas à utilização das TDICs e estratégias para superá-las e também as e dificuldades de utilização (suporte técnico, frequência de utilização, processo de seleção, etc.) [FONSECA 2013].

$\mathrm{Na}$ aplicação do questionário na cidade de Itamaraju, colaboraram 40 professores de matemática, distribuídos por doze escolas públicas, sendo seis delas da rede Municipal e seis da rede Estadual de ensino, o que corresponde a 95\% das escolas da zona urbana e a $90 \%$ do total de professores de matemática do ensino fundamental do município. Em um segundo momento optou-se por aplicar o mesmo questionário para professores de outros estados do Brasil. A ideia era buscar similaridades e analisar o motivo de possíveis diferenças. Nesta etapa, colaboraram 50 professores, oriundos de 39 cidades distribuídas em 15 estados e no Distrito Federal e com representatividade de todas as cinco regiões do território nacional.

Nesta coleta de dados foi possível obter informações que contribuíram para uma análise das dificuldades e desafios na utilização das TDICs no processo de ensino e aprendizagem pelos professores de matemática. Após analisar o resultado das pesquisas foi possível propor o mecanismo para refinamento de buscas na internet apresentado no presente artigo. A ideia surgiu de dois fatores marcantes, os professores, na sua grande maioria, utilizam o Google para buscar TDICs e têm também como prática a necessidade de terem que "se virar sozinho" para utilizar o material educacional escolhido. Sendo assim, a ideia de propor uma ferramenta que auxiliasse o refinamento do processo de busca no Google e ao mesmo tempo buscasse por materiais mais adequados às condições de uso na escola, mostrou-se interessante.

Quando questionados sobre qual forma mais comum para buscarem TDICs, os professores, tanto na pesquisa regional quanto na pesquisa nacional, destacaram o mecanismo de busca Google. O fato dos professores de matemática de Itamaraju apontarem os computadores da própria escola como segunda opção (20\%) deve-se a forma como os técnicos da secretaria de ensino do município preparam os computadores (seleção e instalação de softwares). A Figura 1-a apresenta os gráficos com todos os dados.

Depois de escolhido o recurso educacional, um novo desafio é a utilização em si. Neste sentido, os professores foram indagados sobre o que normalmente fazem para utilizar o recurso educacional (instalação, configuração, disponibilização para os alunos, etc.). Assim como na questão anterior também houve um padrão comum de resposta, a maioria dos professores, independente da sua localização geográfica, indicou que fica por sua única e exclusiva responsabilidade fazer com que o recurso educacional possa 
ser utilizado. O gráfico da Figura 1-b apresenta as repostas para tal indagação. Vale destacar que vários professores da cidade de Itamaraju, mais precisamente $30 \%$, responderam que contam com a ajuda de alguém (técnico, monitor ou colega com maiores conhecimentos em informática) para fazer uso do recurso. Esta resposta vai de encontro com o fato de boa parte dos computadores das escolas já possuírem uma gama significativa de TDICs instalados/disponibilizados.
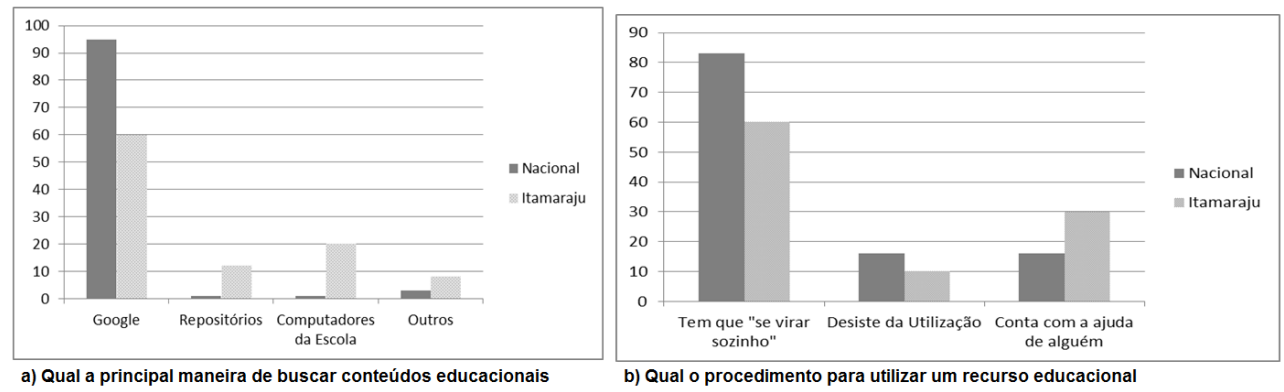

Figura1. Resultados das pesquisas

\section{Ferramenta de Busca}

Devido à falta de infraestrutura de apoio técnico para o uso de laboratórios de informática, formação inadequada de professores para promover a inclusão digital e o processo de informatização das escolas, foi proposto a elaboração de uma solução simples que auxiliasse os professores pré-dispostos a fazer uso das TDICs. Como solução, foi desenvolvida uma ferramenta que serve como uma camada anterior (frontend) para o mecanismo de busca Google, através da qual é solicitado o fornecimento de algumas informações (o que se quer buscar e qual a sua escola) e inseridos pela própria ferramenta alguns parâmetros de pesquisa possíveis para o Google, com a finalidade de refinar a pesquisa a ser realizada e, em consequência disso, apresentar resultados mais relevantes, sempre de forma transparente e pouco intrusiva para o professor. Para realizar tal finalidade, a ferramenta é baseada nos seguintes critérios:

- Informações sobre as condições tecnológicas: envolvendo limitações de memória dos computadores, acesso à internet e softwares existentes (sistema operacional, navegador de internet, etc.). Essas informações devem ser fornecidas pelo responsável técnico da escola e podem ser fornecidas num único momento e utilizadas nas pesquisas dos professores. É o único momento de intervenção de alguém que não seja o professor. Caso essas informações não sejam fornecidas, a pesquisa apresenta resultados mais amplos, ou melhor, menos especializados.

- Informações pedagógicas: conteúdo a ser abordado, seguindo os Parâmetros Curriculares Nacionais (PCN). Na atual versão da ferramenta, esses conteúdos estão limitados aos anos finais do Ensino Fundamental II e são: Números e Operações, Espaço e Forma, Grandezas e Medidas, Tratamento da Informação. Para descrever e representar tais termos foram utilizados conceitos e princípios de ontologia com a finalidade de contribuir para o fornecimento da relação semântica às informações.

- Tipo de TDICs: Vídeo, áudio, jogo, aplicação multimídia, texto, etc.

Pretende-se buscar TDICs que possam ser executadas nos computadores da escola para atender as limitações tecnológicas e as necessidades dos professores 
relacionadas às questões pedagógicas. Desta forma, o resultado da busca é limitado ao universo de TDICs que contêm essas características, fazendo com que o professor não se sinta desorientado ao analisa-lo, nem frustrado por encontrar uma TDIC que, apesar de ser muito interessante, não pode ser utilizada nos laboratórios da escola.

No desenvolvimento da ferramenta foram utilizadas linguagens de programação PHP e HTML. Também foi utilizado um banco de dados MySQL e um servidor Apache para disponibilização do serviço.

\subsection{Funcionamento}

Inicialmente o responsável técnico pela parte de informática da escola deve preencher um formulário informando alguns aspectos sobre o(s) laboratório(s) de informática, tais como, se existe acesso à internet, qual o sistema operacional, se os computadores estão em rede, qual navegador web, se existe caixa de som e microfone nos computadores. Como base nessas informações, nos tópicos dos PCNs enriquecidos com aspectos de ontologia e parâmetros de busca do Google, é disponibilizada a ferramenta para o professor. A tela principal (http://www.eduardobarrere.com/elias/), vide Figuras 2 e 3, permite selecionar conteúdos de interesse do professor de matemática, através de palavras-chaves (termos presentes no PCN e associados ao conteúdo de matemática).

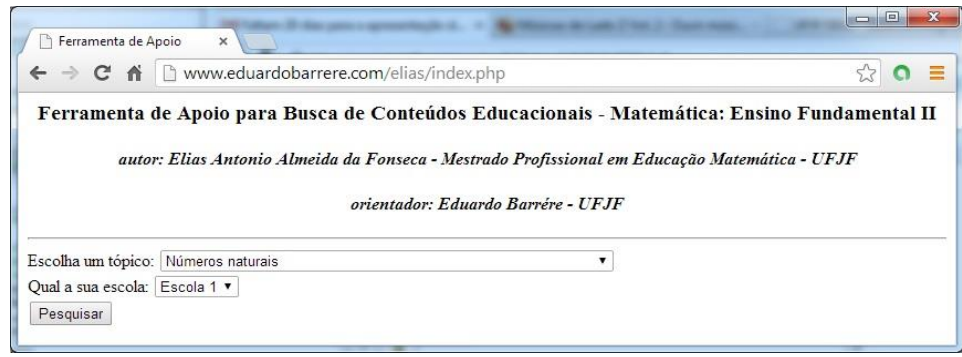

Figura 2. Tela inicial da ferramenta de busca

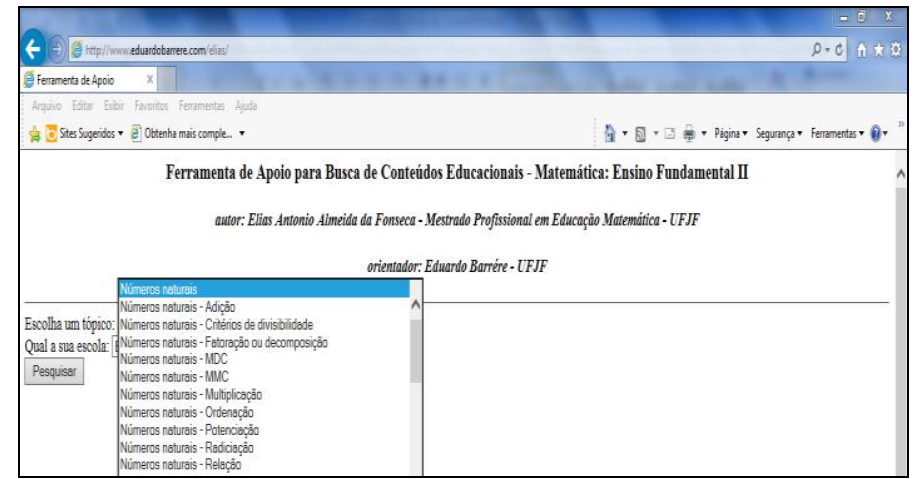

Figura 3. Seleção do tópico de interesse do professor

Após a seleção do tópico, o usuário clica no botão "pesquisar", a ferramenta processará uma busca automaticamente no Google, retornando resultados refinados, que se apresentam conforme padrão de interface do Google, vide exemplo na Figura 4. Desta forma, é realizada uma busca Google considerando diversos aspectos para a composição dos termos e parâmetros de busca com grande impacto no resultado obtido, caso essa mesma pesquisa fosse realizada diretamente pelo professor. 


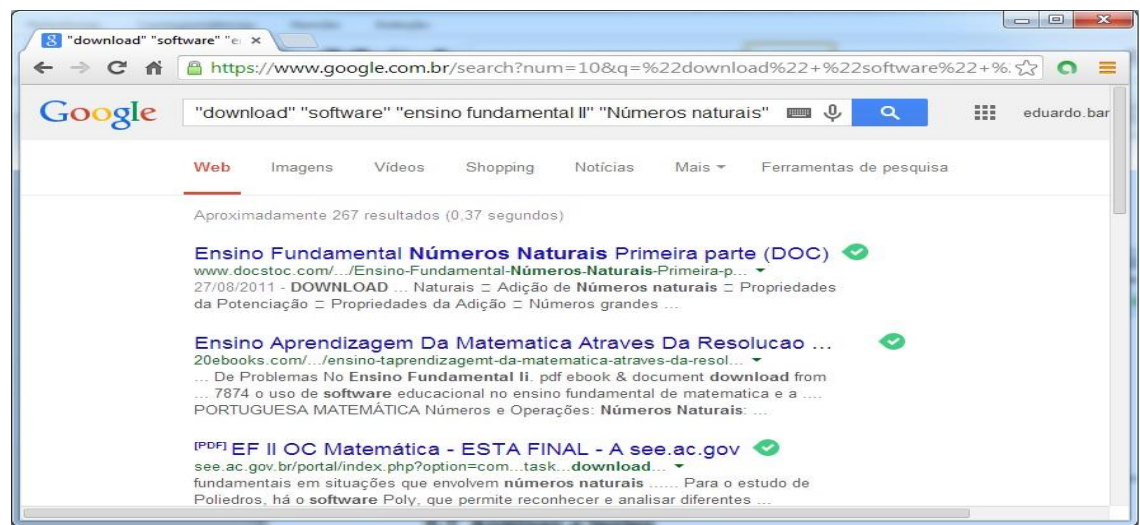

Figura 4. Exemplo de busca realizada pela ferramenta proposta

\subsection{Análise}

Visando analisar a eficiência da ferramenta em aprimorar a busca, incialmente foi realizada uma análise comparativa entre os resultados obtidos com a ferramenta versus as buscas avançadas similares no Google por um conteúdo educacional desenvolvido para o ensino de matemática, mais precisamente softwares educacionais. Para tanto, é feita uma busca geral pelo "tópico" procurado, depois é acrescentado ao termo geral, outro termo e assim sucessivamente. O uso de aspas (““) nos termos justifica-se pelo refinamento da busca no Google, delimitando os resultados retornados. A Tabela 1 apresenta, como exemplo, parte da análise realizada. No total foram 27 tópicos do PCN pesquisados [FONSECA 2014].

Tabela 1. Resultados retornados nas buscas [FONSECA 2014]

\begin{tabular}{|c|c|c|c|c|}
\hline \multirow{3}{*}{ Tópicos } & \multicolumn{3}{|c|}{ Busca Avançada no Mecanismo de Busca Google } & $\begin{array}{c}\text { Busca avançada na } \\
\text { Ferramenta proposta }\end{array}$ \\
\hline & Geral & $\begin{array}{c}\text { Tópico específico para o } \\
\text { ensino fundamental II }\end{array}$ & $\begin{array}{c}\text { Busca Específica por } \\
\text { Softwares sobre o tópico }\end{array}$ & $\begin{array}{c}\text { Busca Específica por } \\
\text { Softwares sobre o tópico }\end{array}$ \\
\hline & ("<tópico>") & $\begin{array}{c}\text { ("<tópico>" + "ensino } \\
\text { fundamental II") }\end{array}$ & $\begin{array}{c}\text { ("<tópico>" + " ensino } \\
\text { fundamental II" + software) }\end{array}$ & $\begin{array}{c}\text { Pesquisa sem o uso de } \\
\text { ontologia }\end{array}$ \\
\hline Números naturais & 256.000 & 7.980 & 3.140 & 164 \\
\hline Números inteiros & 357.000 & 3.760 & 8.740 & 209 \\
\hline Números racionais & 156.000 & 3.600 & 2.780 & 144 \\
\hline Números reais & 295.000 & 9.550 & 7.130 & 117 \\
\hline
\end{tabular}

Embora o Google possua uma grande e volumosa diversidade de dados, estes não estão interligados entre si (ausência dos aspectos da Web Semântica), provocando a falta de correspondência entre os termos digitados. A rapidez com que os dados expandem na Web dificulta a organização e estruturação destes no Google, são milhões de informações que trafegam a cada segundo na rede mundial de computadores. Desse modo, é preciso estruturar as relações semânticas das informações contidas na Web para facilitar a recuperação da informação. Santarém and Vidotti (2011) destacam que a web semântica é aplicada para facilitar a associação entre os termos dentro de uma estrutura sintática da linguagem humana, permitindo a construção de vocábulos, escritas de regras e até mesmo a criação de repositórios de dados na Web.

O mecanismo de busca proposto nesta pesquisa foi desenvolvido com base nos princípios de uma ontologia baseada nos termos do PCN e descrita em Fonseca (2014). Essencialmente, a ideia foi delimitar, conforme os padrões encontrados no PCN de tópicos e conteúdos, um rol de termos que correspondem aos conteúdos e agregam 
"semântica" à busca, por exemplo, utilizar o termo "adição de polinômios" ao invés de "soma de polinômios". A Tabela 2 apresenta um fragmento da análise comparativa ao considerar os termos da ontologia, no total são 207 termos. A análise completa pode ser consultada em Fonseca (2014).

Tabela 2. Comparativo considerando termos da ontologia [FONSECA 2014]

\begin{tabular}{|c|c|c|c|}
\hline & \multirow{2}{*}{$\begin{array}{c}\text { Pesquisa na } \\
\text { Ferramenta proposta } \\
\text { Resultados }\end{array}$} & \multirow{2}{*}{$\begin{array}{c}\text { Busca Específica no Google com o uso de ontologia } \\
\text { "download" +"software"+"ensino fundamental II"+ } \\
\text { "Tópico " + "termo da ontologia" }\end{array}$} \\
\hline Tópico & Termo da ontologia & & \\
\hline \multirow[t]{5}{*}{ Juros } & & 610 & 26.500 .000 \\
\hline & Cálculo & 358 & 6.000 \\
\hline & Comparação & 196 & 1.650 \\
\hline & Descontos & 201 & 5.960 \\
\hline & Operações & 407 & 6.340 \\
\hline
\end{tabular}

A Tabela 3 apresenta um resumo comparativo entre os números totais para o caso da busca somente pelos tópicos do PCN e a busca focada pelos termos especializados sugeridos pela ontologia (gerada a partir do PCN). Destaca-se que, apesar do uso da ontologia, a diminuição no número de resultados apresentados após o uso da ontologia não foi tão significante, apenas $6,58 \%$ em relação à busca sem os termos especializados pela ontologia. Isto se deve ao fato das ações fundamentais para limitação dos números de resultados serem as mesmas para os dois casos e pelo fato do Google já incorporar alguns algoritmos semânticos em seu mecanismo.

Tabela 3. Resumo comparativo dos resultados obtidos nas buscas

\begin{tabular}{|l|r|r|r|r|}
\hline \multirow{2}{*}{} & \multicolumn{2}{|c|}{ Somente os Tópicos } & \multicolumn{1}{c|}{ Termos Especializados } \\
\cline { 2 - 5 } & \multicolumn{1}{|c|}{ Google } & Ferramenta & Google & \multicolumn{1}{c|}{ Ferramenta } \\
\hline Total de buscas realizadas & 27 & 27 & 207 & 207 \\
\hline Quantidades de palavras & 84 & 84 & 2633 & 2633 \\
\hline Resultados retornados & 41.293 .391 .897 & 8.286 & 177.506 & 26.256 \\
\hline Resultado médio por busca realizada & $1.529,39$ & 306,90 & 986 & 146 \\
\hline Diminuição média na quantidade de resultados & \multicolumn{2}{|c|}{$\mathbf{7 9 , 9 3 \%}$} & & $\mathbf{8 5 , 1 9 \%}$ \\
\hline
\end{tabular}

\subsection{Testes com usuários}

Como última etapa para validação da ferramenta, foi realizado um experimento com professores de matemática de duas escolas públicas da cidade de Juiz de Fora - MG, com o objetivo de verificar se os resultados retornados pela ferramenta eram realmente significantes, pois somente diminuir a quantidade de resultados não garante a qualidade dos mesmos. Participaram 20 professores do Ensino Fundamental II.

Baseado em algum dos tópicos das disciplinas de matemática para os dois últimos anos do Ensino Fundamental II, o professor deveria inicialmente fazer uma pesquisa no Google por softwares para auxiliar o ensino daquele tópico, exemplo: software para cálculo de juros. Foram escolhidos e distribuídos aleatoriamente, quatro tópicos diferentes que constam no PCN. Cada professor deveria selecionar os três primeiros resultados (links) que satisfizessem sua pesquisa, consultando resultado por resultado do Google, na ordem de ocorrência e verificar no máximo os 40 primeiros resultados retornados. Depois a pesquisa seria repetida, mas agora com uso da ferramenta desenvolvida. 
Foi contabilizado o esforço para encontrar os três resultados (quantidade de páginas visitadas na ordem de apresentação de resultados do Google) e relevância dos resultados encontrados, ou seja, qual das formas de pesquisa apresentou os melhores resultados (mais relevantes e adequados à pesquisa). A Tabela 4 apresenta os resultados da pesquisa. Vale ressaltar que para cada tópico, cinco professores fizeram sua pesquisa e a tabela apresenta os valores médios entre essas pesquisas.

Tabela 4. Verificação de desempenho da ferramenta por professores

\begin{tabular}{|c|c|c|c|c|c|c|c|}
\hline \multirow[b]{2}{*}{ Tópico } & \multicolumn{2}{|c|}{ Google } & \multicolumn{2}{|c|}{ Ferramenta } & \multirow[b]{2}{*}{$\begin{array}{l}\text { Maior } \\
\text { relevância }\end{array}$} & \multirow{2}{*}{$\begin{array}{c}\text { Diminuição } \\
\text { na qtd. de } \\
\text { páginas } \\
\text { visitadas }\end{array}$} & \multirow{2}{*}{$\begin{array}{c}\text { Aumento } \\
\text { do } \\
\text { sucesso } \\
\text { na busca }\end{array}$} \\
\hline & $\begin{array}{c}\text { Qtd. média } \\
\text { de páginas } \\
\text { visitadas }\end{array}$ & $\begin{array}{c}\text { Sucesso } \\
\text { na Busca } \\
\text { (3 itens) }\end{array}$ & $\begin{array}{c}\text { Qtd. média } \\
\text { de páginas } \\
\text { visitadas }\end{array}$ & $\begin{array}{c}\text { Sucesso } \\
\text { na Busca } \\
\text { (3 itens) }\end{array}$ & & & \\
\hline Cálculo de Juros & 31,5 & 2,67 & 11,5 & 3 & Ferramenta & $63,5 \%$ & $12,5 \%$ \\
\hline Multiplicação de Números Inteiros & 21,0 & 3 & 9,5 & 3 & Ferramenta & $54,8 \%$ & $0,0 \%$ \\
\hline Dízima Periódica & 36,5 & 2,33 & 15,5 & 2,83 & Ferramenta & $57,5 \%$ & $21,3 \%$ \\
\hline MDC & 27,5 & 2,83 & 13,5 & 3 & Ferramenta & $50,9 \%$ & $5,9 \%$ \\
\hline Média Geral & 29,1 & 2,71 & 12,5 & 2,96 & -------- & $56,7 \%$ & $10,0 \%$ \\
\hline
\end{tabular}

A quantidade de páginas visitadas para cada pesquisa, até encontrar os três resultados positivos, foi reduzida aproximadamente pela metade $(56,7 \%)$. Este fato demonstra um menor esforço, pois através da observação dos professores ao montarem as strings de busca (texto a ser pesquisa no Google), foi possível novamente confirmar que está é a grande dificuldade do processo. O insucesso em algumas buscas ocorreu pelo fator subjetivo atrelado à aceitação ou não do resultado apresentado como válido. Também é possível verificar que a ferramenta auxiliou no aumento da obtenção de sucesso no desafio proposto em 10\%. A escolha de qual método foi mais eficiente para a busca, apesar de muito subjetiva, apresentou unanimidade.

\section{Conclusões e Trabalhos Futuros}

A pesquisa inicial tratou das dificuldades em utilizar TDICs por parte dos professores de matemática de escolas públicas do ensino fundamental. $O$ fato de a pesquisa ser inicialmente regional e depois ter sido estendida para outras cidades do território nacional, propiciou uma análise de similaridades e discrepâncias É preciso reconhecer que os professores de outras regiões que participaram da pesquisa, possuem diferentes realidades, diversos aspectos similares de um lado, e diferenças de outro. Nesse sentido, a pesquisa procurou identificar quais os pontos significativos, tais como, como estão lidando com a questão de utilização das TDICs, quais melhorias mais recentemente foram conquistadas, quais os desafios a vencer. Com base nesses dados, foi definida a ferramenta de busca, para ser uma solução computacional de baixo impacto para o professor e que auxilia a especialização da busca por conteúdos na internet.

A bateria de testes (buscas) através da ferramenta em comparação com buscas diretas no Google apresentou bons resultados, pois ao agregar semântica, aspectos técnicos de informática e parâmetros de filtragem à string de busca, permite diminuir significativamente $(85 \%)$ a quantidade de resultados obtidos. Esta pesquisa possibilitou confirmar uma possível diminuição no esforço do professor em encontrar resultados satisfatórios à sua busca e também restringi-los a um conjunto que possa ser utilizado (por restrições técnicas) em sua escola. 
Para complementar e validar a eficiência da ferramenta faltava verificar se a ela trazia os mesmos resultados obtidos em uma busca comum e se alguns desses resultados, por questões de restrições na string de busca, seriam omitidos, mesmo que válidos para o professor. Mesmo sendo uma pesquisa bem restrita no número de participantes e na quantidade de tópicos de busca considerados, foi possível verificar que a ferramenta realmente agrega valor à busca. Mesmo não sendo foco dessa pesquisa, a observação da forma, pouco precisa e técnica, do professor em elaborar a string de busca já justificou o uso da ferramenta. Também foi possível checar que os professores não relataram problemas em usar a busca pela ferramenta, pois a interface é bem simples e intuitiva.

Como proposta de trabalhos futuros pretende-se estender a ferramenta para realizar a busca em outros buscadores na web e em repositórios de Objetos de Aprendizagem. Também seria importante realizar uma nova pesquisa para validação da ferramenta, considerando um número maior de participantes, o registro da forma como o professor realiza a busca e a utilização de uma quantidade maior de tópicos a serem analisados, buscando assim uma análise mais precisa a eficiência da ferramenta. Outra possibilidade é a adequação do mecanismo de busca a outras soluções, como a Federação de Repositórios Educa Brasil - FEB, mantido pela UFRGS.

\section{Referências}

Bairral, M. A. (2013) "As TIC e a licenciatura em matemática: Em defesa de um currículo focado em processos", In: Jornal Internacional de Estudos em Educação Matemática, v. 6, p. 1-20.

Boeri, C. N. and Silva, S.L. (2011) "Novas tecnologias no ensino-aprendizagem da Matemática: o uso da informática", In: XIII Conferência Interamericana de Educação Matemática, Brasil.

Borba, M.C. (2010) "Softwares e internet na Sala de Aula", In: X ENEM - Encontro Nacional de Educação Matemática, Brasil.

Carvalho, S. F. and Scherer, S. (2012) "Formação continuada em serviço e integração da lousa digital em aulas de matemática", In: XI encontro sul-mato-grossense de educação matemática, Brasil.

Castro Filho, J. A. (2007) "Objetos de Aprendizagem e sua utilização no ensino de matemática", In: IX Encontro Nacional de Educação Matemática - Sociedade Brasileira de Educação Matemática, v. 01, Brasil.

Fonseca, E. A. A. and Barrére, E. (2013) "Dificuldades de Utilização das Tecnologias Digitais de informação e Comunicação no Ensino de Matemática.”, In: VII Congresso Iberoamericano de Educação Matemática - CIBEM 2013, ISSN 23010797, Uruguai.

Fonseca, E. A. A. (2014) "Metodologia para Auxiliar Professores de Matemática no Processo de Seleção de Conteúdos Digitais”, Dissertação de Mestrado, Programa de Pós-graduação em Educação Matemática - UFJF.

Santarem, J. E. and Vidotti, S. A. B. G. (2011) "Representação iterativa e folksonomia assistida para repositórios digitais”, In: Liinc em Revista, v. 7, p. 283-300. 